\title{
Assessment of nutritional status of school going children in the age group 7-9 Years
}

Received: 19.11.2015; Revised: 15.05.2016; Accepted: 27.05.2016

See end of the paper for authors' affiliations PARUL BORA

Department of Foods and Nutrition, College of Home Science, Govind

Ballabh Pant University of Agriculture and Technology, PANTNAGAR (UTTARAKHAND) INDIA

Email : parulbora@gmail.com
ABSTRACT : The present study was conducted in Pantnagar, U.S.Nagar district of Uttarakhand state to assess the nutritional status of the school going children. One hundred children of 7-9 years age (50 boys and 50 girls) were selected randomly. Nutritional status of children was assessed in terms of dietary assessment was done by 24 hour dietary recall method for three consecutive days of. The results of the study revealed that consumption of foods like cereals, pulses, fruits, GLV's, milk and milk products, fats and oils, sugar and jaggery were inadequate in the diets of both boys and girls. Nutrients like energy, fat, $\beta$-carotene, B-complex vitamins, vitamin $\mathrm{C}$, iron and calcium were found limiting in the diets of school children. It was found that family size, father's occupation and parent's education had significant $(\mathrm{P}<0.05)$ effect on food intake of selected children. So there is an urgent need to educate mothers of school going children about the importance of balanced diet and preparation of nutrient-rich recipes based on locally available food stuffs in the children's diet to improve their nutritional status. The results of the study can be of use for planning need-based supplementary nutrition programmes by the policy-makers for the school children. Hence it can be concluded that feeding of nutrient rich supplements based on locally available food stuffs can go a long way in improving nutritional status of children which will contribute in the well- being of the children who are the future of the nation's prosperity.

KEY WORDS: School children, Nutritional assessment, Dietary assessment, Micronutrients

- HOW TO CITE THIS PAPER : Bora, Parul and Kulshreshtha, Kalpana (2016). Assessment of nutritional status of school going children in the age group 7-9 Years. Asian J. Home Sci., 11 (1) : 238-245, DOI: 10.15740/HAS/AJHS/11.1/238-245. 